\begin{tabular}{lcccr} 
T H E & A R C H I V E & O F & M E C H A N I C A L & E N G I N E E R I N G \\
\hline VOL. LX & 2013 & Number 3
\end{tabular}

10.2478/meceng-2013-0026

Key words: slender links, rigid finite element method, risers, hydrodynamic forces, internal flow

IWONA ADAMIEC-WÓJCIK *, LUCYNA BRZOZOWSKA **, STANISEAW WOJCIECH ${ }^{* * *}$

\title{
MODIFICATION OF THE RIGID FINITE ELEMENT METHOD IN MODELING DYNAMICS OF LINES AND RISERS
}

\begin{abstract}
The paper presents an application of the modified rigid finite element method to analysis of the dynamics of slender structures. The equations of motion are formulated for a system discretized by means of the method, and discussion is limited to planar systems and large deformations. Slender elements can be found in offshore engineering as lines, cables and risers. In these cases the hydrostatic influence of water and sea currents has to be taken into account. While analyzing dynamics of risers it may also be necessary to consider the flow of fluid inside the riser. The influence of hydrodynamic coefficients and the velocity of the internal flow of fluid on displacements and forces is presented.
\end{abstract}

\section{Introduction}

Modeling of slender elements used in offshore engineering such as lines, cables and risers requires not only bending and longitudinal flexibilities but also large deflections to be considered. Moreover, in the sea environment uplift pressure, drag force, added mass water and, in the case of risers, internal flow of hydrocarbons (petroleum and gas) have to be taken into account. This means that modeling the behavior of slender systems in offshore engineering is often more complicated than modeling cables, ropes and pipes in the air.

In order to model this type of system, different methods are used [1], among which the most popular are the lumped mass and finite element methods. In the lumped mass method [2], inertial features of the systems modeled

\footnotetext{
* University of Bielsko-Biała, ul. Willowa 2, 43-309 Bielsko-Biała, Email: i.adamiec@ath.eu

** University of Bielsko-Biała, ul. Willowa 2, 43-309 Bielsko-Biała, Email: lbrzozowska@ath.eu

*** University of Bielsko-Biata, ul. Willowa 2, 43-309 Bielsko-Biała, Email: swojciech@ath.eu
} 
are reflected by replacing a continuous system by a system of lumped masses. Despite simplifications of the method, it is often used for modeling risers [3]. A similar approach is used in the method called the Flexible Segment Model (FSM) presented in [4].

The finite element method is most often used in dynamic analysis of lines, cables and risers. Many commercial packages both of general use (Abaqus) or specialized for offshore engineering (Riffex or Offpipe) are based on this method. However, new methods of modeling slender systems used in offshore engineering are still being sought for $[5,6,7,8,9]$. This paper, which presents an application of a modification of the rigid finite element method to modeling a planar system with large deformations of links and consideration of longitudinal flexibility, is one of such methods.

Applications of the rigid finite element method (RFEM) in its classical formulation, when the elements have 6 degrees of freedom [10], to modeling of pipes transporting petroleum or gas are presented in [11, 12]. Application of the modification of RFEM in which only bending flexibility of the discretized links is considered [13] to dynamic analysis of a pipe-laying operation by the reel method is presented in $[14,15]$.

This paper continues research [16] and presents two different formulations of a modification of the rigid finite element method enabling us to consider of both bending and longitudinal flexibilities of slender links. In the first, absolute coordinates of rigid elements are used and constraint equations are formulated. In the second paper, the authors abandon the idea of separating the elements and use independent coordinates which lead to a formulation with a much smaller number of generalized coordinates. This paper presents the most important parts of the two formulations and compares their numerical effectiveness. Moreover, the formulation in absolute coordinates is supplemented with relations describing an influence of hydrodynamic forces, and new detailed relations for the internal flow of fluid in the riser are also given. Exemplary numerical simulations demonstrate the influence of drag force, added mass and internal flow of fluid on displacements and forces in the system analyzed.

\section{Modification of RFEM, alternative formulation}

In the modified Rigid Finite Element method used in the analysis of bending vibrations of slender links $[13,14,15,17]$, division into rigid finite elements is carried out as in the classical RFEM [10], presented in Fig. 1. 
a)

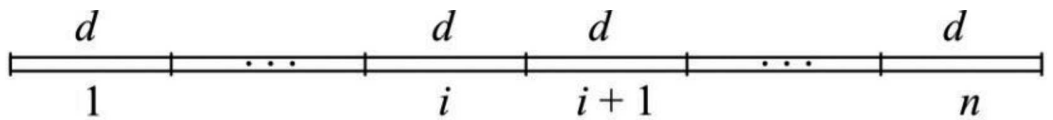

b)

\begin{tabular}{cccccc}
$\mathrm{rfe} 0$ & $\mathrm{rfe} 1$ & \multicolumn{1}{c}{$\mathrm{rfe} i$} & $\mathrm{rfe} n-1$ & $\mathrm{rfe} n$ \\
sde 1 & $\operatorname{sde} 2$ & sde $i$ & sde $i+1$ & sde $n-1$ & sde $n$
\end{tabular}

Fig. 1. Division into rigid finite elements (rfe) and spring-damping elements (sde): a) primary division, b) secondary division

First, the slender beam-like link with length $L$ is divided into $n$ elements with the following lengths:

$$
d=\frac{L}{n}
$$

Then, during the secondary division, massless spring-damping elements (sde), representing bending features of sections with length $d$, are placed in the middle of the rigid elements. When the linear physical relations describe the characteristics of the discretized links, stiffness coefficients are calculated according to the formula:

$$
c_{i}^{b}=\frac{E I}{d}
$$

where: $E$ - Young's modulus of elasticity,

$I$ - inertial moment of the cross-section area.

Rigid finite elements (rfe) are sections of the link placed between sdes or between the ends of the link and sde 1 or $n$ respectively. Thus, the generalized coordinates of the rfe are:

$x_{0}, y_{0}$ - coordinates of point $A_{0}$,

$\varphi_{i}$ - inclination angles of rfe $0 \div n$ towards axis $x$ of the coordinate system (Fig. 2).

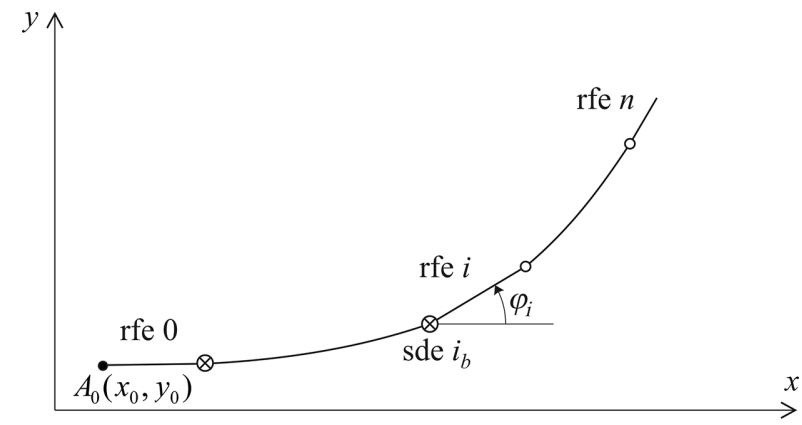

Fig. 2. Generalized coordinates of the slender link with bending flexibility only 
In order to consider longitudinal flexibility too [16], we propose in this paper one more stage of discretization, in which each rfe from Fig. $1 \mathrm{~b}$ is divided into two parts connected by means of an additional sde representing longitudinal flexibility of the rfe described by $\Delta_{i}$ (Fig. 3a).

a)

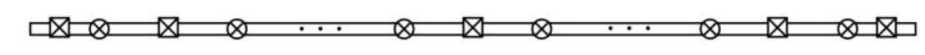

b)

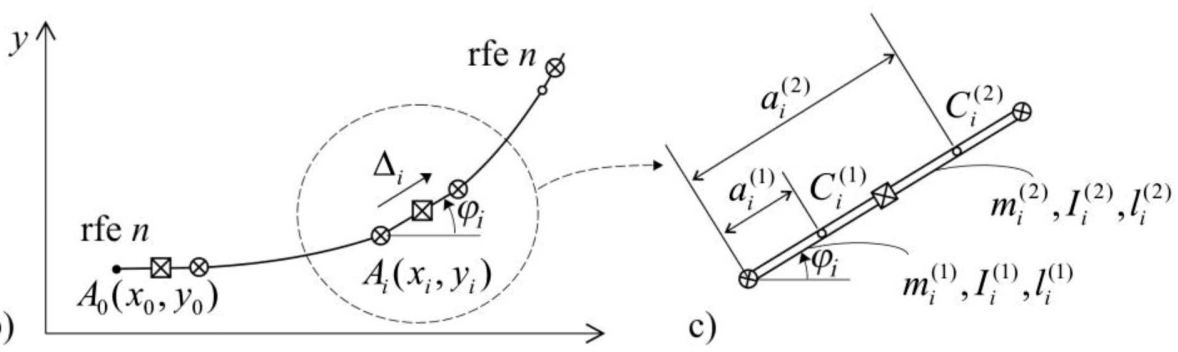

Fig. 3. Modification of RFEM when both bending ad longitudinal flexibilities are considered: a) spring-damping elements for longitudinal flexibility, b) generalized coordinates of rfe $i$, c) geometrical and mass parameters of rfe $i$

Geometrical and mass parameters of parts (1) and (2) $(j=1,2)$ of rfe $i$ are characterized by the following:

$a_{i}^{(j)}-$ distance of the center of mass of part $j$ of $\operatorname{rfe} i$ from point $A_{i}$,

$l_{i}^{(j)}$ - length of part $j$ of rfe $i$,

$I_{i}^{(j)}$ - inertial mass moments of part $j$ of rfe $i$ with respect to their mass centers $C_{i}^{(j)}$.

Longitudinal stiffness coefficients of sde $i$ can be defined from the following relations:

$$
c_{i}^{l}=\frac{E F_{i}}{l_{i}}
$$

where: $F_{i}$ - area of cross-section of rfe $i$,

$l_{i}$ - length of rfe $i$ (without consideration of $\Delta_{i}$ ).

Kinetic and potential energies of the link discretized in the way described above can be presented in the following forms:

- kinetic energy:

$$
T=\sum_{i=0}^{n} \sum_{j=1}^{2} \frac{1}{2}\left\{m_{i}^{(j)}\left[\left(\dot{x}_{c_{i}}^{(j)}\right)^{2}+\left(\dot{y}_{c_{i}}^{(j)}\right)^{2}\right]+I_{i}^{(j)}\left(\dot{\varphi}_{i}\right)^{2}\right\}
$$


- potential energy of bending deformations:

$$
V^{b}=\sum_{i=1}^{n} c_{i}^{b}\left(\varphi_{i}-\varphi_{i-1}\right)
$$

- potential energy of longitudinal deformations:

$$
V^{l}=\sum_{i=0}^{n} c_{i}^{l} \Delta_{i}^{2}
$$

- potential energy of forces of gravity:

$$
V^{g}=\sum_{i=0}^{n} m_{i}^{(j)} y_{c_{i}}^{(j)} g
$$

Equations of motion of the slender link can be derived from the Lagrange equations. First the generalized coordinates of rigid finite elements have to be chosen according to one of the above formulations. Below, a short description of the two approaches is given.

In further considerations, we use the terms absolute and independent coordinates in order to distinguish the approaches presented. In both cases, according to [18], one could use the term mixed coordinates: absolute/joint in the first case and nodal/joint in the second case.

\subsection{Absolute coordinates}

In this case, the motion of rfe 0 to rfe $n$ is described by the vectors:

$$
\mathbf{q}_{i}=\left[\begin{array}{lll}
x_{i} & y_{i} \Delta_{i} & \varphi_{i}
\end{array}\right]^{T} \text { for } i=0,1, \ldots, n .
$$

The equations of motion of rfe $i$ can be written in the form:

$$
\mathbf{M}_{i}^{r} \ddot{\mathbf{q}}_{i}=\mathbf{h}_{i}^{r}+\overline{\mathbf{D}} \mathbf{R}_{i}+\mathbf{D}_{i} \mathbf{R}_{i+1}-\frac{\partial \mathbf{V}^{g}}{\partial \mathbf{q}_{i}}
$$

where: $\mathbf{M}_{i}^{r}-$ mass matrices $4 \times 4$,

$\mathbf{h}_{i}^{r}=\mathbf{h}_{i}^{r}\left(\mathbf{q}_{i}, \dot{\mathbf{q}}_{i}\right)$ - right side vectors $4 \times 1$,

$\overline{\mathbf{D}}, \mathbf{D}_{i}\left(\mathbf{q}_{i}\right)$ - matrices of coefficients $4 \times 2$,

$\mathbf{R}_{i}=\left[\mathbf{R}_{i}^{x}, \mathbf{R}_{i}^{y}\right]^{T}$ - vector of reactions at points $A_{i}$.

Detailed expressions for elements of above vectors and matrices are given in [16]. 
It is assumed that the coordinates of point $A_{0}$ are known:

$$
\left\{\begin{array}{l}
x_{0}=x_{0}(t) \\
y_{0}=y_{0}(t)
\end{array} .\right.
$$

Moreover, the coordinates of rfes have to fulfill the following constraint equations:

$$
\left\{\begin{array}{l}
x_{i+1}=x_{i}+\left(l_{i}+\Delta_{i}\right) \cos \varphi_{i} \\
y_{i+1}=y_{i}+\left(l_{i}+\Delta_{i}\right) \sin \varphi_{i}
\end{array} \quad \text { for } i=0,1, \ldots, n-1\right.
$$

Formulae defining elements of matrices and vectors from the above formulae are defined in [16]. Having completed equations (7) with constraint equations in the acceleration form, we can define the equations of motion of a slender link as:

$$
\begin{gathered}
\overline{\mathbf{M}}_{I} \ddot{\mathbf{q}}_{I}-\mathbf{D} \cdot \mathbf{R}=\mathbf{f}_{I} \\
\mathbf{D}^{T} \ddot{\mathbf{q}}_{I}=\mathbf{g} \\
\mathbf{q}_{I}=\left[\begin{array}{l}
\mathbf{q}_{0} \\
\mathbf{q}_{1} \\
\vdots \\
\mathbf{q}_{n}
\end{array}\right]
\end{gathered}
$$

where: $\overline{\mathbf{M}}_{I}=\operatorname{diag}\left\{\overline{\mathbf{M}}_{0}, \overline{\mathbf{M}}_{1}, \ldots, \overline{\mathbf{M}}_{n}\right\}$,

$\mathbf{D}, \mathbf{R}, \mathbf{f}, \mathbf{g}$ - defined in [16].

A special diagonal form of matrix $\overline{\mathbf{M}}_{I}$ enables an easy calculation of $\overline{\mathbf{M}}_{I}^{-1}$ and then vectors $\ddot{\mathbf{q}}_{I}$ and $\mathbf{R}$.

\subsection{Independent coordinates}

In this case, the components of the following vector are assumed to be generalized coordinates of the slender link:

$$
\mathbf{q}_{I I}=\left[x_{0}, y_{0}, \Delta_{0}, \varphi_{0}, \ldots, \Delta_{i}, \varphi_{i}, \ldots, \Delta_{n}, \varphi_{n}\right]^{T}
$$

The equations of motion of the link take the following form:

$$
\overline{\mathbf{M}}_{I I} \ddot{\mathbf{q}}_{I I}-\mathbf{D R}_{0}=\mathbf{f}_{I I}\left(\mathbf{q}_{I I}, \dot{\mathbf{q}}_{I I}\right)
$$

and from the constraint equations only (7.2) apply.

It should be noted that matrix $\overline{\mathbf{M}}_{I I}$ is full in this case. 


\subsection{Comparison of numerical effectiveness of formulations in absolute and independent coordinates}

Formulation in the absolute coordinates leads to a system with:

- $4 \times(n+1)$ differential equations (8.1),

- $2 \times(n+1)$ equations (8.2).

Mass matrix $\overline{\mathbf{M}}_{I}$ takes a block-diagonal form.

Formulation of the equations of motion using independent coordinates leads to a system with:

- $2 \times(n+2)$ differential equations (10) with full mass matrix,

- 2 constraint equations (7.2).

In order to define how the choice of generalized coordinates influences the numerical effectiveness of the models, computer programs implementing the algorithms have been elaborated. The Runge-Kutta method of the fourth order with a constant integration step has been used for integrating the equations of motion. Systems of linear algebraic equations have been solved by means of the Gauss method with a pivot element.

Motion of mass $m_{s}=1000 \mathrm{~kg}$ hanging on a line with length $L=100$ $\mathrm{m}$ is analyzed. The following parameters of the line are assumed: Young's modulus $E=10^{11} \mathrm{~N} / \mathrm{m}^{2}$; density of the material $\rho=2000 \mathrm{~kg} / \mathrm{m}^{3}$; circular cross-section with radius $R=0.025 \mathrm{~m}$. Initial conditions are shown in Fig. 4 .

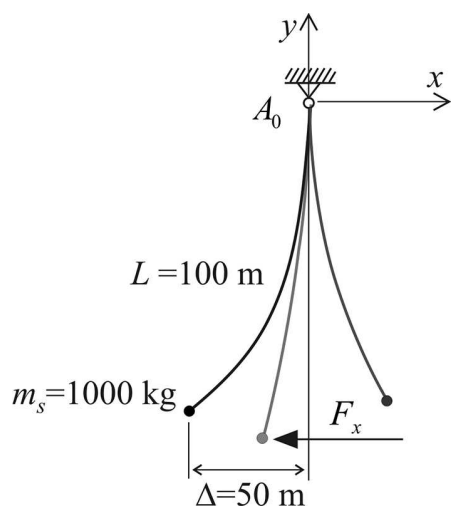

Fig. 4. Mass $m_{s}$ hanging on the line with length $L$

Bending stiffness of sde is omitted, assuming $c_{i}^{b}=0$. A configuration in which mass $m_{s}$ is displaced by $\Delta=50 \mathrm{~m}$ under horizontal force $F_{x}$ is assumed as initial conditions. Calculations are carried out with integration step $h=$ $10^{-4} \mathrm{~s}$ for time $t \in<0,20 \mathrm{~s}>$. Table 1 presents an influence of number $n$ and the method of defining generalized coordinates on the time of calculations.

Analysis of results from Table 1 indicates that, for large $n$, considerably shorter times of calculations are obtained when absolute coordinates are used. 
Influence of definition of generalized coordinates of rfes on numerical effectiveness of dynamic simulations

\begin{tabular}{|c|c|c|c|c|c|c|}
\hline \multirow{2}{*}{$n$} & \multicolumn{3}{|c|}{ Absolute coordinates } & \multicolumn{3}{c|}{ Independent coordinates } \\
\cline { 2 - 7 } & $x_{s}(20 \mathrm{~s})$ & $y_{s}(20 \mathrm{~s})$ & time of calculations & $x_{s}(20 \mathrm{~s})$ & $y_{s}(20 \mathrm{~s})$ & time of calculations \\
\hline 10 & -49.547 & -86.750 & $37^{\prime \prime}$ & -49.549 & -86.750 & $35^{\prime \prime}$ \\
\hline 20 & -49.551 & -86.763 & $1^{\prime} 23^{\prime \prime}$ & -49.552 & -86.762 & $3^{\prime} 18^{\prime \prime}$ \\
\hline 30 & -49.552 & -86.765 & $2^{\prime} 20^{\prime \prime}$ & -49.553 & -86.765 & $10^{\prime} 06^{\prime \prime}$ \\
\hline 40 & -49.552 & -86.765 & $3^{\prime} 30 ”$ & -49.553 & -86.765 & $23^{\prime} 13^{\prime \prime}$ \\
\hline 50 & -49.552 & -86.765 & $4^{\prime} 52^{\prime \prime}$ & -49.553 & -86.765 & $43^{\prime} 13^{\prime \prime}$ \\
\hline 100 & -49.552 & -86.765 & $14^{\prime} 23^{\prime \prime}$ & -49.553 & -86.765 & 5 h32'25” \\
\hline
\end{tabular}

Despite the necessity of considering constraint equations, the diagonal mass matrix definitely increases numerical effectiveness of the algorithm. Taking this into consideration below, only the formulation in absolute coordinates is used for introduction of hydrodynamic forces and internal flow of fluid in risers.

Fig. 5 presents the trajectory of mass $m_{s}$ while Fig. 6 presents a shape of the line at the chosen time points. Differences between $n=10$ and $n=50$ are negligible, and impossible to show in the scale of the figures.

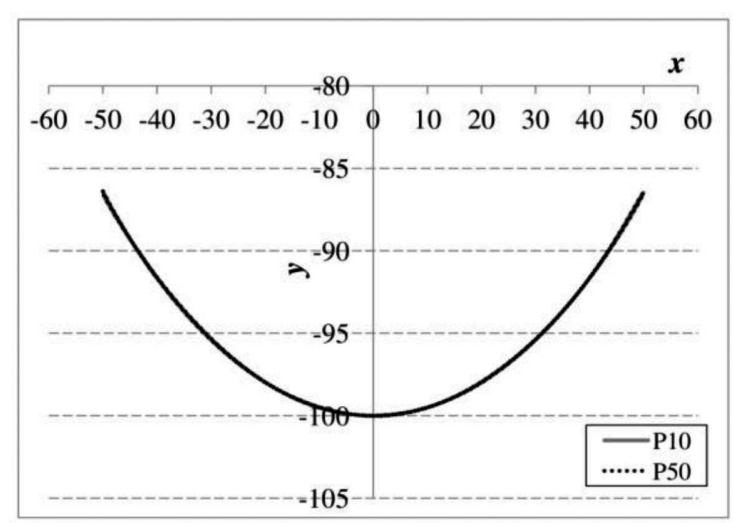

Fig. 5. Trajectory of mass $m_{s}$

It should be underlined that both formulations of the modified rigid finite element method have been verified by comparison of our own results with the analytical solution for a catenary line. The results indicate that an error of $1 \%$ with respect to the exact solution is already obtained for $n=40$. 


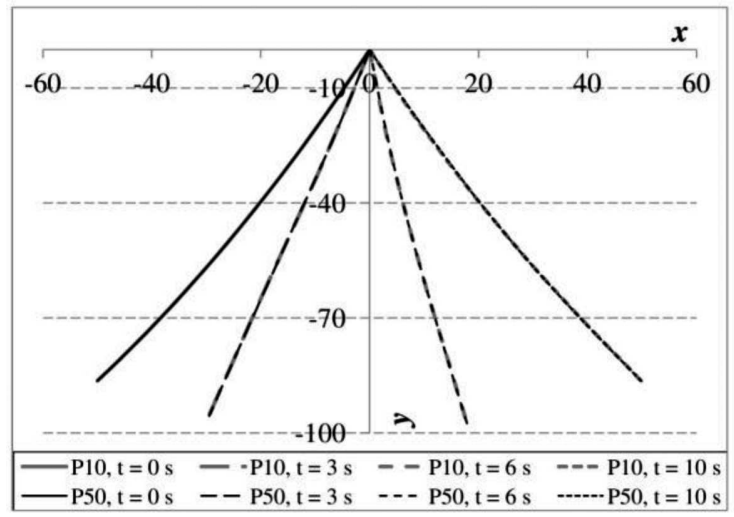

Fig. 6. Shape of the line at chosen moments

\section{Influence of hydrodynamic forces}

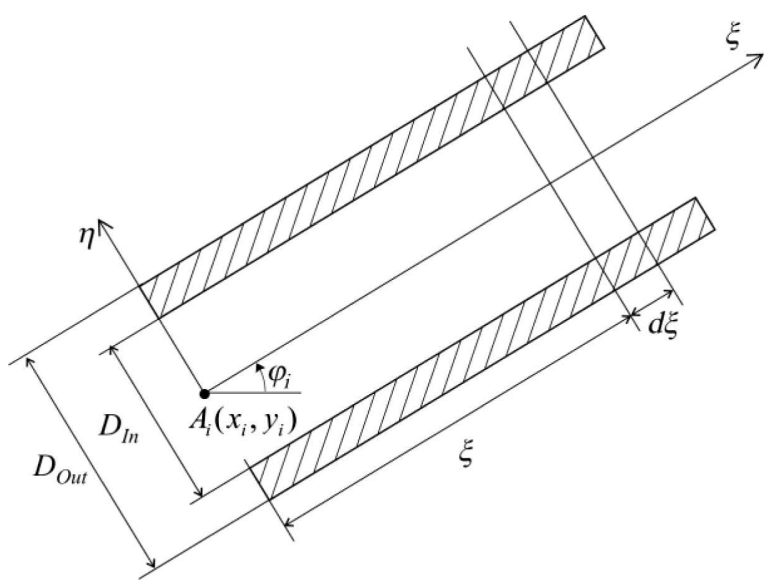

Fig. 7. External $D_{O u t}$ and internal $D_{I n}$ diameter of the riser

When an rfe of the discretized link is submerged, then the following forces act on the segment with length $d \xi$ (Fig. 7):

- uplift pressure and force of gravity [2]:

$$
d \mathbf{F}_{r}=\left[\begin{array}{c}
0 \\
\left(-\rho_{r} A_{r}-\rho_{f} A_{f}+\rho_{w} A_{w}\right)
\end{array}\right] d \xi
$$

where: $\rho_{r}$ - density of the riser (pipe) walls,

$\rho_{f}$ - density of the fluid inside the riser,

$\rho_{w}-$ density of water,

$A_{r}=\frac{\pi}{4}\left[D_{\text {Out }}^{2}-D_{I n}^{2}\right]-$ area of the riser walls, 
$A_{f}=\frac{\pi}{4} D_{I n}^{2}-$ area of fluid flow,
$A_{w}=\frac{\pi}{4} D_{\text {Out }}^{2}-$ external cross-section of the riser;

- drag forces dependent on the velocity of the sea current and element [19]:

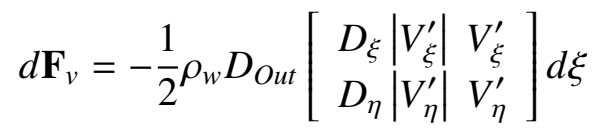

where: $D_{\xi}, D_{\eta}-$ drag coefficients,

$V_{\xi}^{\prime}, V_{\eta}^{\prime}$ - components of velocity $\mathbf{V}^{\prime}=\mathbf{V}^{\prime}{ }_{r}-\mathbf{V}^{\prime}{ }_{w}$,

$\mathbf{V}^{\prime}{ }_{r}, \mathbf{V}^{\prime}{ }_{w}$ - vectors of velocity of the riser and water in coordinate

- inertial forces [19]: system $\{\xi, \eta\}$

$$
d \mathbf{F}_{b}=\left[C_{M} A_{\text {Out }} \rho_{w} \cdot \mathbf{a}_{w}-\left(C_{M}-1\right) A_{\text {Out }} \rho_{w} \cdot \mathbf{a}\right] d \xi
$$

where: $C_{M}$ - inertia coefficient,

$\mathbf{a}_{w}-$ vector of acceleration of water (sea current) in frame $\{\xi, \eta\}$,

$\mathbf{a}-$ vector of acceleration of the riser in frame $\{\xi, \eta\}$;

- interaction forces of the pipe and internal fluid. Further, we show how to take into account this interaction.

Consideration of drag forces dependent on velocity requires introduction of additional vectors into the right side of equations of motion (7):

$$
\mathbf{f}_{i}^{v}=\mathbf{f}_{i}^{v}\left(\mathbf{q}_{i}, \dot{\mathbf{q}}_{i}, \mathbf{V}_{w}\right)
$$

where: $\mathbf{V}_{w}$ - water velocity in the global system.

Consideration of inertial forces leads to the following relation:

$$
\mathbf{f}_{i}^{b}=\mathbf{M}_{i}^{b}\left(\mathbf{q}_{i}\right) \ddot{\mathbf{q}}_{i}+\mathbf{h}_{i}^{b}\left(\mathbf{q}_{i}, \dot{\mathbf{q}}_{i}, \mathbf{a}_{w}\right)
$$

In order to take into account uplift pressure acting on the $i$-th rfe, forces from (11) have to be integrated with respect to the length of both parts of the element, and thus instead of $V^{g}$ from (5.4) the following expression is obtained :

$$
V_{w}^{g}=\left\{\left[A_{i}^{r}+A_{i}^{f}-A_{i}^{w}\right] l_{i}^{(1)} y_{C_{i}}^{(1)}+\left[A_{i}^{r}+A_{i}^{f}-A_{i}^{w}\right] l_{i}^{(2)} y_{C_{i}}^{(2)}\right\} g
$$

where: $y_{C_{i}}^{(1)}=y_{i}+\frac{l_{i}^{(1)}}{2} \sin \varphi_{i}-$ coordinates of the center of the mass of part (1) of rfe $i$,

$$
\begin{aligned}
y_{C_{i}}^{(2)}= & y_{i}+\left(l_{i}^{(1)}+\frac{l_{i}^{(2)}}{2}+\Delta_{i}\right) \sin \varphi_{i}-\text { coordinates of the center of the } \\
& \text { mass of part (2) of rfe } i .
\end{aligned}
$$


Having calculated derivatives $\frac{\partial V_{w}^{g}}{\partial q_{i}}$, they have to be introduced into equations (7) instead of $\frac{\partial V^{g}}{\partial q_{i}}$.

In order to consider the influence of internal fluid flow on the motion of the riser, an approach similar to that presented in [19] is used and this does not require direct definition of interaction forces between the fluid and the riser.

Let $u$ define the velocity of the fluid with respect to the walls of the riser. According to Fig. 8 the kinetic energy of the fluid flowing through rfe $i$ is defined as follows:

$$
T_{i}^{f}=\frac{1}{2} \rho_{l}^{f} \int_{0}^{l_{i}^{(1)}}\left[V_{x, 1}^{2}+V_{y, 1}^{2}\right] d \xi+\frac{1}{2} \rho_{l}^{f} \int_{l_{i}^{(1)}}^{l_{i}}\left[V_{x, 2}^{2}+V_{y, 2}^{2}\right] d \xi
$$

where: $\rho_{l}^{f}=\rho_{f} A_{f}-$ linear density of the fluid,

$V_{x, 1}, \quad V_{y, 1}$ - velocity of the fluid in part (1) of rfe $i$,

$V_{x, 2}, \quad V_{y, 2}-$ velocity of the fluid in part (2) of rfe $i$.

a)

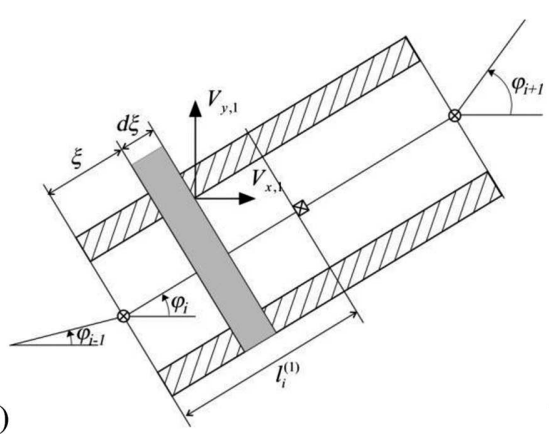

b)

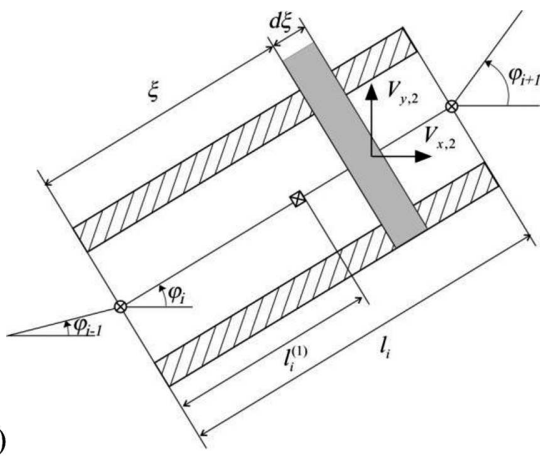

Fig. 8. Velocities of the fluid a) in part (1) of rfe $i, \mathrm{~b})$ in part (2) of rfe $i$

Velocities $V_{x, 1}, \quad V_{y, 1}, V_{x, 2}, \quad V_{y, 2}$ in terms of the absolute coordinates given in (6) are defined by the relations:

$$
\begin{gathered}
V_{x, 1}=\dot{x}_{i}-\xi \dot{\varphi}_{i} s \varphi_{i}+u_{i, x}^{(1)} \\
V_{y, 1}=\dot{y}_{i}+\xi \dot{\varphi}_{i} c \varphi_{i}+u_{i, y}^{(1)} \\
V_{x, 2}=\dot{x}_{i}+\dot{\Delta}_{i} c \varphi_{i}-\left(\xi+\Delta_{i}\right) \dot{\varphi}_{i} s \varphi_{i}+u_{i, x}^{(2)} \\
V_{y, 2}=\dot{y}_{i}+\dot{\Delta}_{i} s \varphi_{i}+\left(\xi+\Delta_{i}\right) \dot{\varphi}_{i} c \varphi_{i}+u_{i, y}^{2}
\end{gathered}
$$


where: $u_{x}, u_{y}$ - are components of relative velocity of the fluid in the inertial system,

$$
c \varphi_{i}=\cos \varphi_{i}, s \varphi_{i}=\sin \varphi_{i}
$$

Components $u_{x}, u_{y}$ in the inertial system depend on angle $\varphi$ of inclination of the central line of the riser towards axis $x$ of the global frame of reference.

It is assumed that:

$$
\begin{aligned}
& \mathbf{u}_{i}^{(1)}=\left[\begin{array}{l}
u_{i, x}^{(1)} \\
u_{i, y}^{(1)}
\end{array}\right]=u\left[\begin{array}{c}
\alpha_{i, 1}(\xi) c \varphi_{i-1}+\beta_{i, 1}(\xi) c \varphi_{i} \\
\alpha_{i, 1}(\xi) s \varphi_{i-1}+\beta_{i, 1}(\xi) s \varphi_{i}
\end{array}\right] \\
& \mathbf{u}_{i}^{(2)}=\left[\begin{array}{l}
u_{i, x}^{(2)} \\
u_{i, y}^{(2)}
\end{array}\right]=u\left[\begin{array}{c}
\alpha_{i, 2}(\xi) c \varphi_{i}+\beta_{i, 2}(\xi) c \varphi_{i+1} \\
\alpha_{i, 2}(\xi) s \varphi_{i}+\beta_{i, 2}(\xi) s \varphi_{i+1}
\end{array}\right]
\end{aligned}
$$

where: $\alpha_{i, 1}=1-\frac{\xi}{l_{i}^{(1)}}, \beta_{i, 1}=\frac{\xi}{l_{i}^{(1)}}$,

$$
\alpha_{i, 2}=1-\frac{\xi-l_{i}^{(1)}}{l_{i}-l_{i}^{(1)}}, \quad \beta_{i, 1}=\frac{\xi-l_{i}^{(1)}}{l_{i}-l_{i}^{(1)}}
$$

If we assume that functions $u^{(1)}$ and $u^{(2)}$ take form (19), the following conditions are fulfilled:

$$
\begin{gathered}
\left.\mathbf{u}\right|_{\xi=0}=u\left[\begin{array}{c}
c \varphi_{i-1} \\
s \varphi_{i-1}
\end{array}\right] \\
\left.\mathbf{u}\right|_{\xi=l_{i}^{(1)}}=u\left[\begin{array}{c}
c \varphi_{i} \\
s \varphi_{i}
\end{array}\right] \\
\left.\mathbf{u}\right|_{\xi=l_{i}}=u\left[\begin{array}{c}
c \varphi_{i+1} \\
s \varphi_{i+1}
\end{array}\right]
\end{gathered}
$$

which means that the continuity of $\mathbf{u}$ between rfes $i-1, i, i+1$ is preserved. 
Bearing in mind the above assumptions, the kinetic energy of the fluid flowing through rfe $i$ can be expressed as:

$$
\begin{aligned}
T_{i}^{f}= & \frac{1}{2} m_{i}^{f} \dot{x}_{i}^{2}+\frac{1}{2} m_{i}^{f} \dot{y}_{i}^{2}+\frac{1}{2} m_{i, 2}^{f} \dot{\Delta}_{i}^{2}+I_{i}^{f} \dot{\varphi}_{i}^{2} \\
+ & \frac{1}{2} u^{2}\left\{m_{i, 1}^{f}\left[\frac{2}{3}+\frac{1}{3} \cos \left(\varphi_{i-1}-\varphi_{i}\right)\right]+m_{i, 2}^{f}\left[\frac{2}{3}+\frac{1}{3} \cos \left(\varphi_{i}-\varphi_{i+1}\right)\right]\right\} \\
+ & \dot{x}_{i}\left\{m_{i, 1}^{f}\left[-\dot{\varphi}_{i} A_{i, 0} s \varphi_{i}+\frac{u}{2}\left(c \varphi_{i-1}+c \varphi_{i}\right)\right]\right. \\
& \left.+m_{i, 2}^{f}\left[\dot{\Delta}_{i} c \varphi_{i}-\left(\Delta_{i}+B_{i, 0}\right) \dot{\varphi}_{i} s \varphi_{i}+\frac{u}{2}\left(c \varphi_{i}+c \varphi_{i+1}\right)\right]\right\} \\
& +\dot{y}_{i}\left\{m_{i, 1}^{f}\left[\dot{\varphi}_{i} A_{i, 0} c \varphi_{i}+\frac{u}{2}\left(s \varphi_{i-1}+s \varphi_{i}\right)\right]\right. \\
& \left.+m_{i, 2}^{f}\left[\dot{\Delta}_{i} s \varphi_{i}+\left(\Delta_{i}+B_{i, 0}\right) \dot{\varphi}_{i} c \varphi_{i}+\frac{u}{2}\left(s \varphi_{i}+s \varphi_{i+1}\right)\right]\right\} \\
& +u \dot{\varphi}_{i}\left[m_{i, 1}^{f} A_{i, 1} \sin \left(\varphi_{i-1}-\varphi_{i}\right)-m_{i, 2}^{f}\left(\frac{1}{2} \Delta_{i}+B_{i, 1}\right) \sin \left(\varphi_{i}-\varphi_{i+1}\right)\right] \\
& +m_{i, 2}^{f} \dot{\Delta}_{i} \frac{u}{2}\left[1+\cos \left(\varphi_{i}-\varphi_{i+1}\right)\right]
\end{aligned}
$$

where: $m_{i, 1}^{f}=\rho_{l}^{f} l_{i}^{(1)}, m_{i, 2}^{f}=\rho_{l}^{f}\left(l_{i}-l_{i}^{(1)}\right), m_{i}^{f}=m_{i .1}^{f}+m_{i, 2}^{f}$,

$$
\begin{gathered}
A_{i, 0}=\frac{1}{2} l_{i}^{(1)}, \quad A_{i, 1}=\frac{1}{6} l_{i}^{(1)}, \\
B_{i, 0}=\frac{1}{2}\left(l_{i}+l_{i}^{(1)}\right), \quad B_{i, 1}=\frac{1}{6}\left(2 l_{i}+l_{i}^{(1)}\right), \\
I_{i}=\frac{1}{3} m_{i, 1}^{f}\left(l_{i}^{(1)}\right)^{2}+m_{i, 2}^{f} \Delta_{i}\left(\Delta_{i}+2 B_{0}\right)+\frac{1}{3} m_{i, 2}^{f}\left(l_{i}^{2}+l_{i} l_{i}^{(1)}+\left(l_{i}^{(1)}\right)^{2}\right) .
\end{gathered}
$$

It should be noted that kinetic energy $T_{i}^{f}$ of the fluid flowing through rfe $i$ of the riser depends not only on components of vector $\mathbf{q}_{i}=\left[x_{i}, y_{i}, \Delta_{i}, \varphi_{i}\right]^{T}$, but also on $\varphi_{i-1}$ and $\varphi_{i+1}$. Since the kinetic energy of the fluid flowing through all rfes can be expressed as:

$$
T^{f}=\sum_{i=0}^{n} T_{i}^{f} \text { for } i=0, \ldots, n
$$

where $T_{i}^{f}$ defined in (21) and the Lagrange operators are as follows:

$$
\varepsilon_{\mathbf{q}_{i}}\left(T^{f}\right)=\frac{d}{d t} \frac{\partial T^{f}}{\partial \dot{\mathbf{q}}_{i}}-\frac{\partial T^{f}}{\partial \mathbf{q}_{i}}=\mathbf{M}_{i}^{f} \ddot{\mathbf{q}}_{i}+\mathbf{h}_{i}
$$


where:

$$
\begin{aligned}
& \mathbf{M}_{i}^{f}=\mathbf{M}_{i}^{f}\left(\mathbf{q}_{i}\right)=\left[\begin{array}{cccc}
m_{i}^{f} & 0 & m_{i, 2}^{f} c \varphi_{i} & -A_{i} s \varphi_{i} \\
0 & m_{i}^{f} & m_{i, 2}^{f} s \varphi_{i} & A_{i} c \varphi_{i} \\
m_{i, 2}^{f} c \varphi_{i} & m_{i, 2}^{f} s \varphi_{i} & m_{i, 2}^{f} & 0 \\
-A_{i} s \varphi_{i} & A_{i} c \varphi_{i} & 0 & I_{i}^{f}
\end{array}\right], \\
& A_{i}=m_{i}^{f} A_{0}+m_{i, 2}^{f}\left(\Delta_{i}+B_{i, 0}\right) \text {, } \\
& \mathbf{h}_{i}=\mathbf{h}_{i}\left(\mathbf{q}_{i-1}, \mathbf{q}_{i}, \mathbf{q}_{i+1}\right)=\left[\begin{array}{c}
h_{i, 1}^{f} \\
h_{i, 2}^{f} \\
h_{i, 3}^{f} \\
h_{i, 4}^{f}
\end{array}\right], \\
& h_{i, 1}^{f}=-2 m_{i, 2}^{f} \dot{\Delta}_{i} s \varphi_{i}-\dot{\varphi}_{i}^{2} A_{i} c \varphi_{i} \\
& +\frac{u}{2}\left\{-m_{i, 1}^{f}\left[\dot{\varphi}_{i-1} s \varphi_{i-1}+\dot{\varphi}_{i} s \varphi_{i}\right]-m_{i, 2}^{f}\left[\dot{\varphi}_{i} s \varphi_{i}+\dot{\varphi}_{i+1} s \varphi_{i+1}\right]\right\}, \\
& +\frac{\dot{u}}{2}\left\{m_{i, 1}^{f}\left[c \varphi_{i-1}+c \varphi_{i}\right]+m_{i, 2}^{f}\left[c \varphi_{i}+c \varphi_{i+1}\right]\right\} \\
& h_{i, 2}^{f}=2 m_{i, 2}^{f} \dot{\Delta}_{i} \dot{\varphi}_{i} c \varphi_{i}-\dot{\varphi}_{i}^{2} A_{i} s \varphi_{i} \\
& +\frac{u}{2}\left\{m_{i, 1}^{f}\left[\dot{\varphi}_{i-1} c \varphi_{i-1}+\dot{\varphi}_{i} c \varphi_{i}\right]+m_{i, 2}^{f}\left[\dot{\varphi}_{i} c \varphi_{i}+\dot{\varphi}_{i+1} c \varphi_{i+1}\right]\right\}, \\
& +\frac{\dot{u}}{2}\left\{m_{i, 1}^{f}\left[s \varphi_{i-1}+s \varphi_{i}\right]+m_{i, 2}^{f}\left[s \varphi_{i}+s \varphi_{i+1}\right]\right\} \\
& h_{i, 3}^{f}=m_{i, 2}^{f}\left\{-\left(\Delta_{i}+B_{i, 0}\right) \dot{\varphi}_{i}^{2}+\frac{u}{2} \dot{\varphi}_{i+1} \sin \left(\varphi_{i}-\varphi_{i+1}\right)\right. \\
& \left.+\frac{\dot{u}}{2}\left[1+\cos \left(\varphi_{i}-\varphi_{i+1}\right)\right]\right\} \\
& h_{i, 4}^{f}=2 m_{i, 2}^{f}\left(\Delta_{i}+B_{i, 0}\right) \dot{\Delta}_{i} \dot{\varphi}_{i}+m_{i}^{f} \frac{u}{2}\left(\dot{x}_{i} s \varphi_{i}-\dot{y}_{i} c \varphi_{i}\right) \\
& +m_{i, 1}^{f} A_{i, 1}\left[\dot{u} \sin \left(\varphi_{i-1}-\varphi_{i}\right)+\dot{\varphi}_{i-1} u \cos \left(\varphi_{i-1}-\varphi_{i}\right)\right] \\
& -m_{i, 2}^{f}\left(\frac{1}{2} \Delta_{i}+B_{i, 1}\right)\left[-\dot{u} \sin \left(\varphi_{i}-\varphi_{i+1}\right)+u \dot{\varphi}_{i+1} \cos \left(\varphi_{i}-\varphi_{i+1}\right)\right] \text {, } \\
& -\frac{1}{6} u^{2}\left[m_{i, 1}^{f} \sin \left(\varphi_{i-1}-\varphi_{i}\right)-m_{i, 2}^{f} \sin \left(\varphi_{i}-\varphi_{i+1}\right)\right] \\
& +h_{i, L}+h_{i, R} \\
& \dot{u}=\frac{d u}{d t} \text {. }
\end{aligned}
$$

Quantities $h_{i, L}$ and $h_{i, R}$ occurring in formulae for $h_{i, 4}^{f}$ are defined as:

$$
h_{i, L}= \begin{cases}0 & \text { if } i=0 \\ -\frac{\partial T_{i-1}^{f}}{\partial \varphi_{i}} & \text { if } i>0\end{cases}
$$




$$
h_{i, R}= \begin{cases}0 & \text { if } i=n \\ -\frac{\partial T_{i+1}^{f}}{\partial \varphi_{i}} & \text { if } i<0\end{cases}
$$

where:

$$
\begin{aligned}
-\frac{\partial T_{i-1}^{f}}{\partial \varphi_{i}}=- & m_{i-1,2}^{f} u\left\{\frac{u}{6} \sin \left(\varphi_{i-1}-\varphi_{i}\right)+\frac{1}{2}\left(\dot{x}_{i-1} \sin \varphi_{i}-\dot{y}_{i-1} \cos \varphi_{i}\right)\right. \\
+ & \left.\frac{\dot{\Delta}_{i-1}}{2} \sin \left(\varphi_{i-1}-\varphi_{i}\right)+\left(\frac{\Delta_{i-1}}{2}+B_{i-1}\right) \dot{\varphi}_{i-1} \cos \left(\varphi_{i-1}-\varphi_{i}\right)\right\} \\
-\frac{\partial T_{i+1}^{f}}{\partial \varphi_{i}}= & m_{i+1,1}^{f} u\left\{\frac{u}{6} \sin \left(\varphi_{i}-\varphi_{i+1}\right)-\frac{1}{2}\left(\dot{x}_{i+1} \sin \varphi_{i}-\dot{y}_{i+1} \cos \varphi_{i}\right)\right. \\
& \left.-A_{i+1,1} \dot{\varphi}_{i+1} \cos \left(\varphi_{i}-\varphi_{i+1}\right)\right\}
\end{aligned}
$$

In view of relation (19), formulae for $h_{i, 4}^{f}$ contain expressions $u^{2} \sin \left(\varphi_{i-1}-\varphi_{i}\right)$ and $u^{2} \sin \left(\varphi_{i}-\varphi_{i+1}\right)$ proportional to the square of relative velocity of the fluid and curvature of the riser defined by the differences of angles $\varphi_{i-1}-\varphi_{i}$ and $\varphi_{i}-\varphi_{i+1}$.

If apart from hydrostatic forces $\mathbf{f}_{i}^{v}$ and $\mathbf{f}_{i}^{b}$ we also consider forces caused by internal flow of fluid in the riser, the equations of motion of rfe $i$ can be written as:

$$
\mathbf{M}_{i} \ddot{\mathbf{q}}_{i}=\overline{\mathbf{D}} \mathbf{R}_{i}-\mathbf{D}_{i} \mathbf{R}_{i+1}+\mathbf{f}_{i}
$$

where: $\mathbf{M}_{i}=\mathbf{M}_{i}^{v}-\mathbf{M}_{i}^{b}+\mathbf{M}_{i}^{f}$,

$$
\mathbf{f}_{i}=-\mathbf{h}_{i}^{v}+\mathbf{f}_{i}^{v}+\mathbf{h}_{i}^{b}-\mathbf{h}_{i}^{f}-\frac{\partial V_{w}^{g}}{\partial \mathbf{q}_{i}}
$$

Constraint equations take forms (7.2) and (7.3).

\section{Numerical simulations}

In order to define the influence of hydrostatic coefficients on dynamics of the riser we consider a situation in which an initial position of the riser is defined in Fig.9a, and then it is moved along axis $x$ assuming that velocity $\dot{x}_{0}$ changes as in Fig. $9 \mathrm{~b}$.

Geometrical and mass data of the riser and values of coefficients are given in Table 2.

Calculations are carried out for $n=50$, for $t \in<0,200 \mathrm{~s}>$ with an integration step $10^{-3} \mathrm{~s}$. It is assumed that all rfes are submerged in the sea.

Fig. 10 presents the course of trajectory of point $A$ for different values of drag coefficients $D_{\eta}$, assuming $C_{M}=2$. It can be seen that the value of this coefficient considerably influences the motion of the riser. 


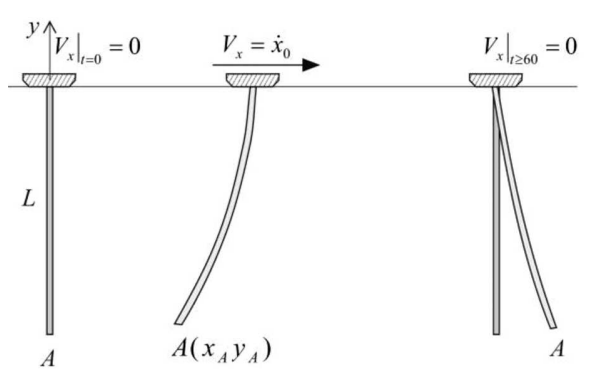

a)

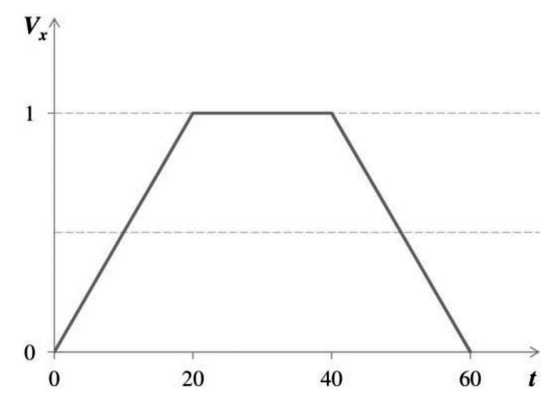

b)

Fig. 9. Displacement of the riser a) motion of the vessel, b) velocity course $v_{x}=\dot{x}_{0}$

Parameters of the system

\begin{tabular}{|c|c|c|c|}
\hline Parameter & Denotation & Value & Unit \\
\hline Length of the riser & $L$ & 500 & $\mathrm{~m}$ \\
\hline External diameter & $D_{\text {Out }}$ & 0.50 & $\mathrm{~m}$ \\
\hline Internal diameter & $D_{\text {Inn }}$ & 0.45 & $\mathrm{~m}$ \\
\hline Young's modulus & $E$ & $2.07 \cdot 10^{11}$ & $\mathrm{~N} / \mathrm{m}^{2}$ \\
\hline Density of the riser & $\rho_{r}$ & 7850 & $\mathrm{~kg} / \mathrm{m}^{3}$ \\
\hline Density of water & $\rho_{w}$ & 1025 & $\mathrm{~kg} / \mathrm{m}^{3}$ \\
\hline Density of the fluid & $\rho_{f}$ & 0 & \\
\hline Resistance coefficients & $D_{\xi}$ & 0 & \\
\hline & $D_{\eta}$ & $\underline{0.7 ; 1.0 ; 1.3}$ & \\
\hline & $C_{M}$ & $1.0 ; 1.5 ; 2.0$ & \\
\hline Velocity of the sea current & $V_{w}$ & 0 & \\
\hline Acceleration of the sea current & $a_{w}$ & 0 & \\
\hline
\end{tabular}

Table 2 .

The influence of inertial forces (together with the added mass) on calculation results is presented in Fig. 11. We compared results for $C_{M}=1, C_{M}=1.5$ and $C_{M}=2$, assuming that $D_{\eta}=0.7$. It can be seen that the influence of $C_{M}$ is less obvious.

Calculations for a pipe with length $L=170 \mathrm{~m}$ laid by J-lay method (Fig. 12) are carried out in order to examine the way in which internal flow of fluid influences displacements and forces acting on the riser. 

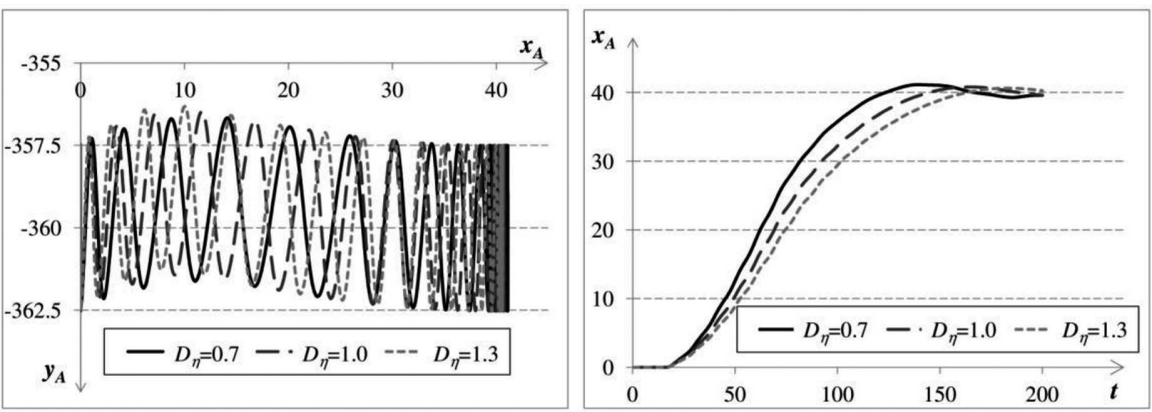

Fig. 10. Influence of drag coefficients $D_{\eta}$ on trajectory of point $A$
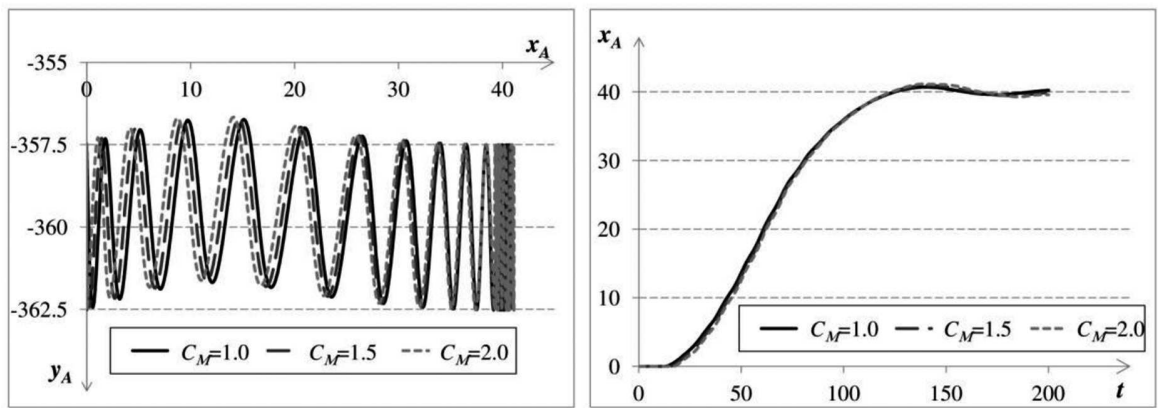

Fig. 11. Influence of coefficient $C_{M}$ on trajectory of point $A$

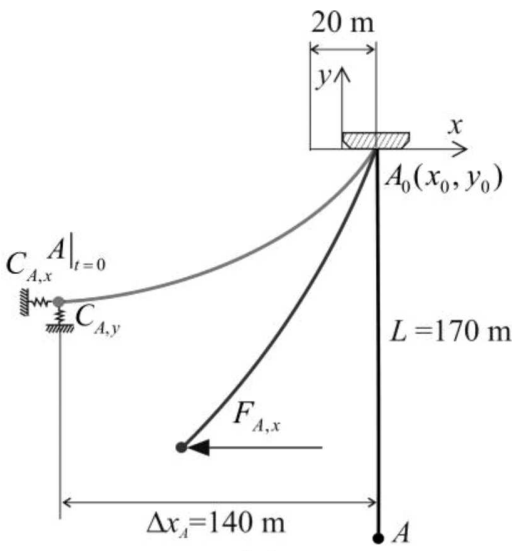

Fig. 12. Displacement of the riser to an initial position

To obtain the position of the riser as in Fig.12 for $\left.A\right|_{t=0}$, we solved the static problem of shifting end $A$ of the riser by means of force $F_{A, x}$ until the following relation is fulfilled:

$$
x_{0}-x_{A}=\Delta x_{A}=140 \mathrm{~m}
$$

Parameters of the system are given in Table 3 . 
Parameters of the system with fluid flow

\begin{tabular}{|c|c|c|c|}
\hline Parameter & Denotation & Value & Unit \\
\hline Length of the riser & $\mathrm{L}$ & 170 & $\mathrm{~m}$ \\
\hline External diameter & $D_{\text {Out }}$ & 0.30 & $\mathrm{~m}$ \\
\hline Internal diameter & $D_{I n n}$ & 0.26 & $\mathrm{~m}$ \\
\hline Density of the fluid & $\rho_{f}$ & 840 & $\mathrm{~kg} / \mathrm{m}^{3}$ \\
\hline \multirow[t]{2}{*}{ Drag coefficients } & $D_{\eta}$ & 0.7 & \\
\hline & $C_{M}$ & 2.0 & \\
\hline \multirow[t]{2}{*}{ Stiffness coefficients } & $C_{E, x}$ & $10^{7}$ & $\mathrm{~N} / \mathrm{m}$ \\
\hline & $C_{E, y}$ & $10^{6}$ & $\mathrm{~N} / \mathrm{m}$ \\
\hline Velocity of the fluid & $u$ & $0 ; 5 ; 10$ & $\mathrm{~m} / \mathrm{s}$ \\
\hline
\end{tabular}

It is assumed that the motion of point $A_{0}$ is defined by the relations:

$$
\begin{gathered}
x_{0}=10 \cos \left(\frac{2 \pi}{27} t\right)[\mathrm{m}], \\
y_{0}=0[\mathrm{~m}] .
\end{gathered}
$$

Calculations have been carried out for $n=40$ which means that the riser is divided into 41 elements. Fig. 13 shows the comparison of the longitudinal force and the trajectory of the middle of the riser when $\rho_{f}=0$ (no fluid inside the riser) as well as $\rho_{f}=840 \mathrm{~kg} / \mathrm{m}^{3}$ and $u=0$ (the riser is filled with no movable fluid).
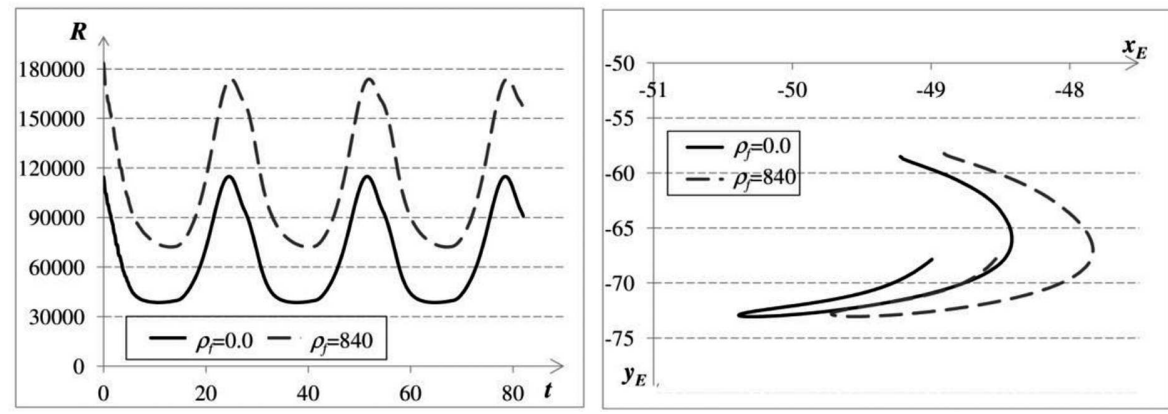

Fig. 13. Influence of the internal fluid mass on the results of calculations: a) longitudinal force inside the riser, b) trajectory of the middle point of the riser

The influence of the velocity of the internal fluid flow $u$ on the results of calculations are presented in Fig.14 (for $u=0 ; u=5 \mathrm{~m} / \mathrm{s} ; u=10 \mathrm{~m} / \mathrm{s}$ ). 
a)
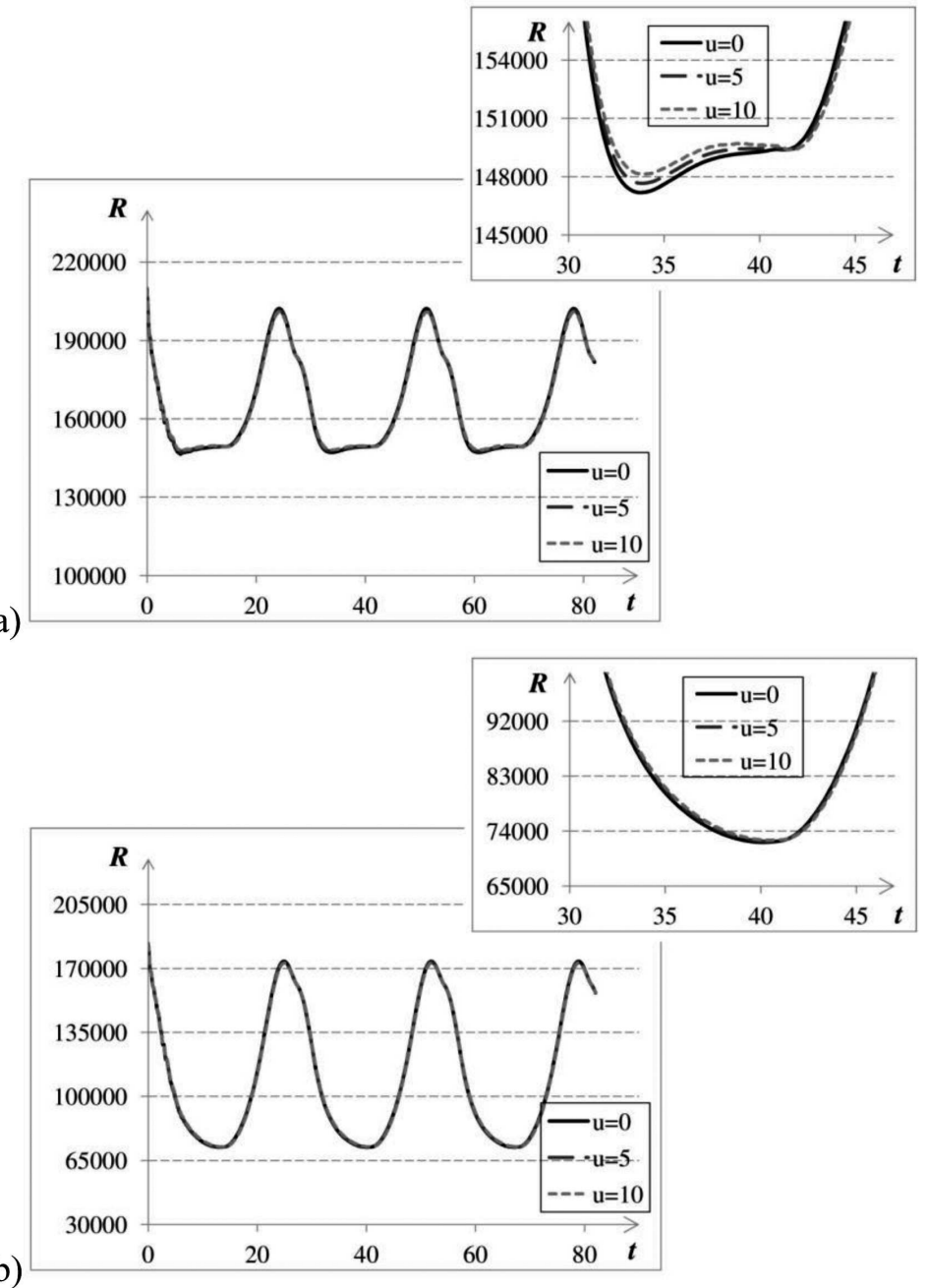

Fig. 14. Influence of the velocity of the fluid flow $u$ on results of calculations a) rfe 0 , b) rfe 20

Longitudinal forces are compared at rfe 0 and 20 which means close to point $A_{0}$ and in the middle of the riser.

The influence of the flow velocity $u$ on the longitudinal force (tension of the riser) is below $1 \%$.

\section{Final remarks}

The paper presents an application of the modification of the rigid finite element method to modeling of dynamics of risers. It is shown that the formulation using absolute coordinates is considerably more numerically efficient. We also discuss how viscous and hydrodynamic forces of the fluid flowing 
inside the riser can be considered. Results of numerical simulations indicate the large influence of drag forces (coefficient $D_{\eta}$ ) on displacements while the riser is shifted. The influence of coefficient $C_{M}$ characterizing an inertial resistance is much smaller. According to test calculations, the influence of the velocity of the internal flow $u$ on values of the tension force is about $1 \%$. It should be noted that this influence can be as large as $15 \%$ [20] when velocity $u$ changes and curvature of the riser is large.

\section{Manuscript received by Editorial Board, November 28, 2012;} final version, February 25, 2013.

\section{REFERENCES}

[1] Patel M.H., Seyed F.B.: Review of flexible riser modelling ana analysis techniques, Engineering Structures, 1995, Vol. 17, No. 4, pp. 293-304.

[2] Raman-Nair W., Baddour R.: Three-dimensional dynamics of a flexible marine riser undergoing large elastic deformations. Multibody System Dynamics, 2003, 10, pp. 393-423.

[3] Liping S., Bo Q.: Global analysis of a flexible riser. Journal of Marine Science and Application, 2011, 10, pp. 478-484.

[4] Xu X., Wang S.: A flexible-segment-model-based dynamics calculation method for free hanging marine risers in re-entry. China Ocean Engineering, 2012, 26, pp. 139-152.

[5] Jensen G.A., Säfström N., Nguyen T.D., Fossen T.F.: A nonlinear PDE formulation for offshore vessel pipline installation, Ocean Engineering, 2000, 37, pp. 365-377.

[6] Park H-I., Jung D-H.: A finite element method for dynamic analysis of long slender marine structures under combined parametric and forcing excitations, Ocean Engineering, 2002, 29, pp. 1313-1325.

[7] Niedzwecki J.M., Liegre P.-Y.F.: System identification of distributed-parameter marine riser models, Ocean Engineering, 2003, 30, pp. 1387-1415.

[8] Chen H., Xu S., Guo H.: Nonlinear analysis of flexible and steel catenary risers with internal flow and seabed interaction effects, Journal of Marine Science and Application, 2011, 10 , pp. 156-162.

[9] Chai Y.T., Varyani K.S.: An absolute coordinate formulation for three-dimensional flexible pipe analysis, Ocean Engineering, 2006, 33, pp. 23-58.

[10] Wittbrodt E., Adamiec-Wójcik I., Wojciech S.: Dynamics of flexible multibody systems: rigid finite element method, Berlin: Springer, 2006.

[11] Szczotka M.: The rigid finite element method in modeling of nonlinear offshore systems.(in Polish) - Gdańsk University of Technology Publishing Office, Monographs 107, Gdańsk, 2011.

[12] Wittbrodt E., Szczotka M., Maczyński A., Wojciech S.: Rigid finite element method in analysis of dynamics of offshore structures. Springer-Verlag, Berlin Heidelberg, 2012.

[13] Wojciech S.: Dynamics of planar linkage mechanisms with considerations of both flexible links and friction as well as clearance in joints. (in Polish) - Publishing Office of the Technical University of Łódź, Monographs 66, Łódź, 1984.

[14] Szczotka M., Wojciech S., Maczyński A.: Mathematical model of a pipelay spread. The Archive of Mechanical Engineering 2007, Vol. 54, Iss. 1, pp. 27-46.

[15] Szczotka M.: Pipe laying simulation with an active reel drive. Ocean Engineering 2010, 37, pp. 539-548. 
[16] Adamiec-Wójcik I., Wojciech S., Wittbrodt E.: Rigid finite element method in modeling of bending and longitudinal vibrations of ropes, International Journal of Applied Mechanics and Engineering 2012, Vol. 17, No. 3, pp. 665-676.

[17] Adamiec-Wójcik I., Wojciech S.: Application of the rigid finite element method in dynamic analysis of plane manipulators, Mech. Mach. Theory 1993, Vol. 28, No. 3, pp. 327-334.

[18] Shabana A.A.: Dynamics of multibody systems, Second Edition, Cambridge University Press, 1998.

[19] Kaewunruen S., Chiravatchradej J., Chucheepsakul S.: Nonlinear free vibrations of marine risers/pipes transporting fluid. Ocean Engineering, 2005, 32, pp. 417-440.

[20] Larsen C.M.: Flexible riser analysis - Comparison of results from computer programs, Marine Structures, 1992, 5, pp. 103-119.

\section{Modyfikacja metody sztywnych elementów skończonych w modelowaniu dynamiki lin i riserów}

\section{Streszczenie}

W pracy przedstawiono zastosowanie zmodyfikowanej metody elementów skończonych do analizy dynamiki wiotkich struktur. Sformułowano równania ruchu układu dyskretyzowanego prezentowaną metodą, przy ograniczeniu rozważań do płaskich układów i uwzględnieniu dużych ugięć. Elementy wiotkie spotykane są często w technice offshore'owej jako liny, kable i risery. Analizę dynamiki tych elementów trzeba jednak wówczas uzupełnić o hydrostatyczne oddziaływania wody i prądów morskich. W przypadków riserów, należy też uwzględnić możliwość przepływu płynu w ich wnętrzu. Na przykładzie risera pokazano wpływ współczynników hydrodynamicznych i prędkości przepływu płynu we wnętrzu risera na przemieszczenia i siły. 